Molthan, A. L., J. R. Bell, T. A. Cole, and J. E. Burks, 2014: Satellite-based identification of tornado damage tracks from the 27 April 2011 severe weather outbreak. J. Operational Meteor., 2 (16), 191-208, doi: http://dx.doi.org/10.15191/nwajom. $\underline{2014.0216 .}$.

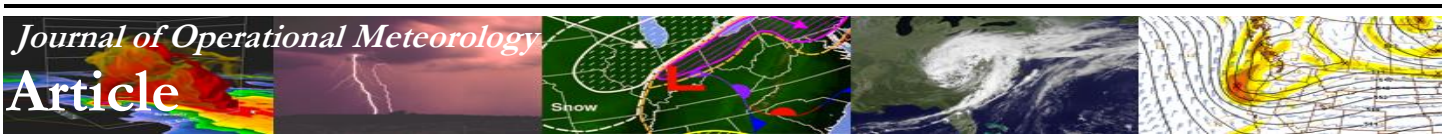

\title{
Satellite-Based Identification of Tornado Damage Tracks from the 27 April 2011 Severe Weather Outbreak
}

\author{
ANDREW L. MOLTHAN \\ NASA Marshall Space Flight Center/Earth Science Office, Huntsville, Alabama \\ JORDAN R. BELL \\ Department of Atmospheric Science, University of Alabama in Huntsville, Huntsville, Alabama \\ TONY A. COLE \\ NASA Internship Program/University of Southern Maine, Portland, Maine \\ JASON E. BURKS \\ NASA Marshall Space Flight Center/Earth Science Office, Huntsville, Alabama
}

(Manuscript received 22 November 2013; review completed 25 April 2014)

\begin{abstract}
The 27 April 2011 severe weather outbreak included 62 tornadoes across northern and central Alabama, leading to one of the largest post-event survey operations in history. The enormity of the task faced by National Weather Service surveyors required extensive planning in an attempt to ensure that every tornado was documented. Moderate- and high-resolution satellite imagery can support the assessment process. Normalized difference vegetation index (NDVI) imagery from the Moderate Resolution Imaging Spectroradiometer, Enhanced Thematic Mapper Plus, and Advanced Spaceborne Thermal Emission and Reflection Radiometer was used to assess satellite-based capabilities to detect tornado damage tracks, expanding upon previous studies of tornado-track detection. Of the tornadoes that were officially documented and surveyed in Alabama, $22(32.4 \%)$ were identified at least in part by a simple visual inspection of single-day NDVI imagery. Detection of satellite-based damage tracks improved for tornadoes with estimated maximum damage of $\geq E F-2$, with portions of $21(65.6 \%)$ paths identified. Lengths of satellite-detected tornado tracks compared favorably $\left(R^{2}=0.88-0.93\right)$ to official survey measurements, but maximum estimated widths compared less favorably $\left(\mathbf{R}^{2}=\mathbf{0 . 3 9 - 0 . 5 2}\right)$. Longer-term NDVI change and image-enhancement techniques, such as principal component analysis, can improve visual inspection. Overall, this study demonstrates that near real-time access to moderate- and high-resolution imagery may support survey activities, particularly in well-vegetated regions where spectral bands and high spatial resolution allow for detection of vegetation damage resulting from severe weather.
\end{abstract}

\section{Introduction}

The 27 April 2011 severe weather outbreak was one of the deadliest and costliest weather events within the United States - part of a broader 4-day period of 25-28 April that produced some 350 tornadoes and 321 fatalities. On 27 April, severe weather was focused primarily in central and northern Alabama, occurring mainly within the county warning areas (CWAs) of the National Weather Service (NWS) Weather Forecast Offices (WFOs) in Huntsville and
Birmingham. Knupp et al. (2014) summarized three distinct periods of severe weather that occurred on 27 April. In the early morning, a quasi-linear convective system (QLCS) and embedded mesovortex moved through northern and central Alabama, producing 29 tornadoes, including three EF-3s in west-central Alabama (Fig. 1). From mid-morning to early afternoon, a second QLCS moved through northern Alabama and produced seven EF-0 and EF-1 tornadoes in Limestone and Madison Counties. Mid-afternoon to mid-evening

Corresponding author address: Andrew L. Molthan, NASA Marshall Space Flight Center / Earth Science Office, 320 Sparkman Drive, Huntsville, AL 35805

E-mail: andrew.molthan@nasa.gov 


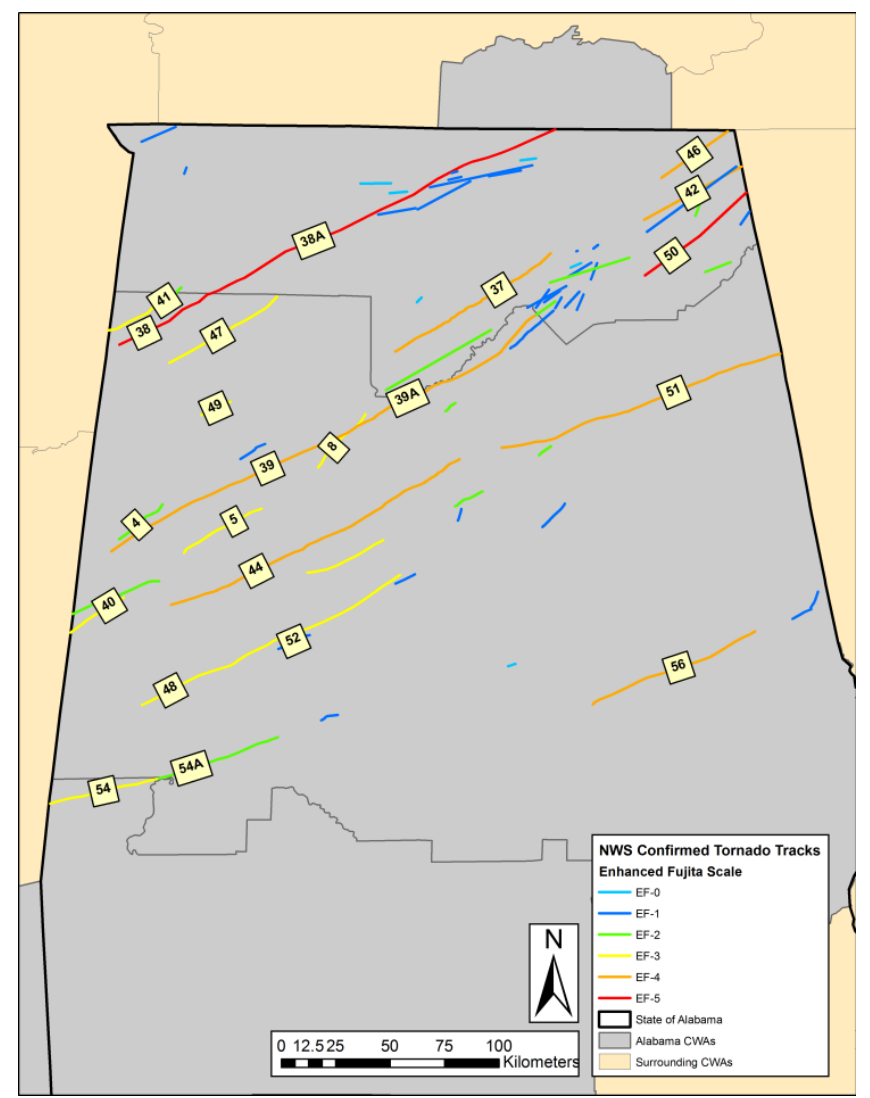

Figure 1. Distribution of NWS field surveys across AL. Numbered tracks correspond to tornadoes identified in the official survey and by satellite. Numbers are based upon the legend contained within statewide GIS data of tornado surveys provided by NWS Birmingham (NWS 2011). Information for tracks not labeled is available from Huntsville and Birmingham WFO survey data. Note that portions of tracks crossing CWA boundaries are assigned the same number but appended with an additional character. Numbers correspond to track details summarized in Table 1. Click image for an external version; this applies to all figures hereafter.

storms consisted of a series of supercells that moved across the state, which produced the majority of the EF-2 to EF-5 tornadoes. In total, Alabama was struck by 62 tornadoes on 27 April, leading to 234 fatalities, numerous injuries, and widespread infrastructure damage that included a weeklong power outage in the Huntsville metropolitan area [National Oceanic and Atmospheric Administration (NOAA 2011); Knupp et al. 2014]. The events of 27 April had a substantial impact across the rest of the southeastern United States, with storms also producing damage and fatalities across Mississippi, Tennessee, Georgia, and Virginia. Combined, Alabama and other southeastern states reported $>2400$ injuries and $>\$ 4$ billion in damage attributed to the storms on 27 April (NOAA 2011).

Efforts to survey single tornadoes or relatively small outbreaks may only require a limited number of staff and use of local resources. Larger "outbreak" events with multiple strong, long-track tornadoes present challenges requiring additional support (Speheger et al. 2003). Following the events of 27 April, NWS meteorologists from the Huntsville and Birmingham WFOs worked with their colleagues in the local research and emergency management communities to conduct field surveys of the affected areas. Widespread availability of digital cameras, smartphones, tablets, and mobile laptop computing provided a means of efficiently aggregating survey information, including geotagging of photographs and other notes regarding damage locations. During the surveys of 27 April, a few teams used the NOAA/NWS Damage Assessment Toolkit (DAT; Camp et al. 2010), which is a smartphone and tablet-based application that records survey information into a geographic information system (GIS). As survey information and data were accumulated, they were compared against damage indicators within the enhanced Fujita scale (EF-scale; Texas Tech University 2004) to estimate the intensity of the wind speed and tornado at specific locations. Surveyors accumulated damage indicators along each damage path, establishing a map and outline of the overall damage area. In a few cases, damage indicators were provided with enough spatial detail that contours of varying EF-scale could be estimated along the track. However, most tracks were defined by outlining the observed damage area and assigning an overall, maximum estimated EF-scale. The NWS surveyors used the overall length of the damage path to estimate the tornado path length, and the width was estimated by measuring perpendicularly across the track at the widest point. Widths were rounded to the nearest 0.40 $\mathrm{km}(0.25 \mathrm{mi})$ in final reporting.

For tornadoes that crossed CWA boundaries, the adjoining WFOs collaborated to ensure that the tracks and ratings were aligned across their boundaries, but each CWA retained a separately named track for their area. The splitting of a single, long-track tornado into components within the boundaries of each CWA resulted in a total count of 68 surveyed tornado paths among the 62 reported tornadoes. For example, a longtrack EF-5 tornado impacted Hackleburg, Phil Campbell, and northern parts of the Huntsville, Alabama, metropolitan area-occurring in both the Huntsville and Birmingham CWAs. In the final survey data, the overall track was split at the CWA boundary, with each component assigned a separate name (Hackleburg, \#38, and Phil Campbell, \#38A) and estimated maximum EF-scale (Table 1). The WFO in Birming- 
Table 1. Distribution of all tornadoes surveyed by the NWS WFOs in Huntsville, Birmingham, and Mobile, AL, and identified with MODIS, ETM+, or ASTER imagery. Cells with N/A indicate where a given sensor did not detect a track. Italicized measurements for ASTER identify officially surveyed tracks where imagery was not available for the entire track length.

\begin{tabular}{|c|c|c|c|c|c|c|c|c|c|c|}
\hline \multirow{2}{*}{ Tornado Name } & \multirow{2}{*}{$\begin{array}{c}\text { Track } \\
\text { Number }\end{array}$} & \multirow{2}{*}{$\begin{array}{l}\text { EF- } \\
\text { Scale }\end{array}$} & \multicolumn{4}{|c|}{ Length (km) } & \multicolumn{4}{|c|}{ Max Width (km) } \\
\hline & & & $\begin{array}{c}\text { NWS } \\
\text { Survey }\end{array}$ & $\begin{array}{c}\text { Terra } \\
\text { MODIS } \\
\end{array}$ & $\begin{array}{c}\text { Landsat-7 } \\
\text { ETM+ }\end{array}$ & $\begin{array}{c}\text { Terra } \\
\text { ASTER }\end{array}$ & $\begin{array}{c}\text { NWS } \\
\text { Survey }\end{array}$ & $\begin{array}{c}\text { Terra } \\
\text { MODIS } \\
\end{array}$ & $\begin{array}{c}\text { Landsat-7 } \\
\text { ETM+ }\end{array}$ & $\begin{array}{c}\text { Terra } \\
\text { ASTER }\end{array}$ \\
\hline Hackleburg & 38 & 5 & 40.79 & 28.58 & 26.45 & 24.29 & 1.21 & 1.22 & 1.08 & 0.94 \\
\hline Lakeview-Rainsville-Cartersville & 50 & 5 & 54.20 & 47.67 & 46.88 & 37.53 & 1.21 & 1.52 & 1.40 & 1.21 \\
\hline Phil Campbell & $38 \mathrm{~A}$ & 5 & 152.57 & 103.33 & 123.17 & 105.50 & 2.01 & 1.59 & 1.98 & 1.33 \\
\hline Bridgeport & 46 & 4 & 32.99 & N/A & 14.84 & 13.13 & 1.21 & N/A & 0.77 & 0.68 \\
\hline Arkadelphia & $39 \mathrm{~A}$ & 4 & 6.65 & 7.63 & 6.97 & 6.48 & 0.40 & 0.96 & 0.86 & 0.72 \\
\hline Cordova & 39 & 4 & 197.58 & 146.65 & 144.20 & 149.47 & 1.21 & 1.06 & 0.97 & 1.08 \\
\hline Cullman & 37 & 4 & 75.44 & 48.82 & 60.28 & 60.44 & 1.61 & 0.70 & 0.99 & 0.75 \\
\hline Lake Martin & 56 & 4 & 71.68 & 63.96 & 63.38 & 22.58 & 0.80 & 1.17 & 1.07 & 1.00 \\
\hline Section-Flat Rock, GA & 42 & 4 & 44.15 & 40.66 & 44.15 & 40.90 & 1.61 & 1.40 & 1.33 & 1.57 \\
\hline Shoal Creek-Ohatchee-Argo & 51 & 4 & 115.78 & 93.50 & 80.81 & 66.30 & 1.61 & 1.77 & 1.56 & 1.87 \\
\hline Tuscaloosa-Birmingham & 44 & 4 & 130.68 & 115.53 & 116.65 & 122.53 & 2.38 & 1.67 & 1.10 & 1.47 \\
\hline Haleyville & 47 & 3 & 51.03 & 47.46 & 40.86 & 49.98 & 1.21 & 0.67 & 0.68 & 0.57 \\
\hline Holman & 5 & 3 & 36.49 & N/A & 26.08 & 26.13 & 0.64 & N/A & 0.63 & 0.63 \\
\hline Hubbertville & 49 & 3 & 12.86 & N/A & 11.37 & 12.19 & 0.80 & N/A & 0.47 & 0.56 \\
\hline Northern Choctaw & 54 & 3 & 43.11 & 36.23 & 42.48 & 42.67 & 0.91 & 1.30 & 0.93 & 0.79 \\
\hline Panola & 40 & 3 & 26.14 & 7.42 & 16.10 & 16.08 & 0.97 & 0.72 & 0.57 & 0.75 \\
\hline Parrish-Cordova & 8 & 3 & 30.81 & N/A & N/A & 13.51 & 0.34 & N/A & N/A & 0.34 \\
\hline Sawyerville-Eoline & 48 & 3 & 116.78 & 110.94 & 111.20 & 111.09 & 1.61 & 1.13 & 1.16 & 1.22 \\
\hline Shottsville & 41 & 3 & 31.55 & 30.56 & 31.28 & 32.05 & 1.29 & 0.98 & 0.65 & 0.56 \\
\hline Northern Reform & 4 & 2 & 23.11 & N/A & 7.47 & 11.42 & 1.13 & N/A & 0.49 & 0.47 \\
\hline Pinhook & $54 \mathrm{~A}$ & 2 & 50.84 & N/A & 11.17 & 19.65 & 0.32 & N/A & 0.61 & 0.45 \\
\hline Wateroak & 52 & 1 & 13.90 & 27.82 & 28.16 & 27.81 & 0.27 & 0.47 & 0.53 & 0.54 \\
\hline
\end{tabular}

ham published damage surveys for all of Alabama in GIS formats following their post-event analysis (NWS 2011). Our understanding of survey procedures was based upon conversations with D. Nadler, warning coordination meteorologist at the Huntsville WFO, and experiences of coauthor J. Burks during his participation in 27 April damage assessments. The official NOAA Service Assessment for the 25-28 April 2011 severe weather events provides a broader overview of NWS efforts supporting preparedness, warning, disaster response, and final storm surveys (NOAA 2011).

In the immediate aftermath of the 27 April storms, the National Aeronautics and Space Administration (NASA) Short-term Prediction Research and Transition Center (SPoRT; Jedlovec 2013) provided satellite imagery to WFOs in Huntsville and Birmingham. Products included short-term differences in red-visible and near-infrared wavelength reflectance observed at 250-m spatial resolution by the Moderate Resolution Imaging Spectroradiometer (MODIS) aboard NASA's Terra and Aqua satellites, and higher-resolution (15 m) false-color composites of red, green, and near-infrared reflectance from the Advanced Spaceborne Thermal Emission and Reflection Radiometer (ASTER) aboard Terra. Meteorologists used the imagery to reevaluate surveys in areas that were inaccessible from the ground, and to correct errors in tracks that were assigned with different end points by separate survey teams (Molthan et al. 2011). Satellite images were proven useful when products were easy to interpret, provided with minimum latency, and solved various issues arising from the original surveys.

Applications of MODIS and ASTER imagery described in Molthan et al. (2011) focused on the use of moderate- to high-resolution images featuring spectral bands in the red-visible and near-infrared wavelengths that are useful for monitoring vegetation and the land surface. These bands are used to derive the normalized difference vegetation index (NDVI), defined as the normalized difference of near-infrared and red-visible reflectance as follows:

$$
N D V I=\frac{\left(R_{N I R}-R_{V I S}\right)}{\left(R_{N I R+} R_{V I S}\right)},
$$

where $R_{\mathrm{NIR}}\left(R_{\mathrm{VIS}}\right)$ represents reflectance in the nearinfrared (red-visible) wavelength. NDVI relates to the greenness or health of vegetation within each pixelused to monitor rapid or long-term change. The resulting NDVI values are unitless and range from -1.0 to 
+1.0. Areas of urban or suburban development and bare earth will have values ranging from 0.0 to 0.2 ; reflectance characteristics of clouds in the visible and near-infrared will produce negative values; and water bodies will have an NDVI near zero. Temperate and tropical forests will have an NDVI ranging from 0.6 to 0.8 , or higher (Tucker and Gatlin 1984), as $R_{\mathrm{NIR}}$ for healthy tree leaves is much higher than $R_{\text {VIS }}$. Agricultural areas will have an NDVI range from near 0.2 to 0.3 as the influence of bare soil in an instantaneous field of view reduces the difference between $R_{\mathrm{NIR}}$ and $R_{\mathrm{VIS}}$ (Tucker and Gatlin 1984).

Prior to the 27 April event, NDVI and other image-processing techniques had been explored to provide satellite-based detection of damage resulting from severe weather. Yuan et al. (2002; hereafter Y02) used $23.5-\mathrm{m}$ resolution imagery from the Linear Imaging Self-Scanning III (LISS-III) sensor aboard the Indian Remote Sensing satellite to examine post-event land surface scarring resulting from the 3 May 1999 tornado event in Oklahoma City, Oklahoma. Their use of satellite imagery focused on three techniques: (i) examination of single-day NDVI for identifying damage scars, (ii) image enhancements using principal component analysis to improve scar detection, and (iii) further improvements via NDVI change derived from pre- and post-storm imagery. Each technique demonstrated at least some skill in identifying portions of the damage area confirmed by a highly detailed ground survey. Single-day NDVI imagery registered damage scars as contiguous paths of pixels with reduced values, and corresponded to changes in the land surface resulting from destroyed vegetation or the presence of debris. Post-event NDVI imagery highlighted urban (rural) damage areas corresponding to F2 (F3) categories within the damage survey. Principal component analysis created three new images, each ranked by their ability to characterize the overall variation present within the scene and among the input green, red, and near-infrared bands. The second principal component (PC2) explained $21 \%$ of the variation throughout the image and produced the greatest contrast between damaged and undamaged areas. Using PC2, tornado damage in urban (rural) areas was detected at the $\geq F$ 3 $(\geq F 4)$ damage levels. Differencing the post-storm NDVI from values two years prior markedly improved damage detection. Relatively small decreases in NDVI were more apparent, resulting from damaged vegetation, movement of dirt, and deposited debris. Whereas PC2 focused on $\geq \mathrm{F} 3$ damage, and single-day NDVI imagery could detect some F2 areas, the NDVI-change image provided more robust detections and allowed inference of damage within some damage zones at $\geq \mathrm{F} 1$.

Myint et al. (2008) analyzed the same 3 May 1999 tornado using imagery from the Landsat-5 Thematic Mapper (TM) at 28.5-m spatial resolution. Pre- and post-event images were combined into multiple principal components using the six TM bands present in the visible and near-infrared spectrum. Various false-color combinations of the resulting principal components were developed to improve damage detection. In addition, pre- and post-event images were differenced for individual bands and used to highlight damage areas. Myint et al. (2008) applied supervised and unsupervised image-classification techniques to refine damage detections, but summarized final results only in terms of damaged and undamaged areas rather than a detailed examination of detections in various Fscales. False-color combinations of principal components and image-classification techniques produced damage-detection accuracies as high as $98 \%$, but their use of proprietary software precluded the examination of their techniques in this study. Image-enhancement techniques - such as histogram fitting and clustering of similar pixels-improved track identification, but characterizations were focused on identifying damaged and undamaged areas rather than on detailed classification of skill as a function of F-scale damage.

Jedlovec et al. (2006; hereafter J06) used imagery from MODIS, ASTER, and the Landsat-7 Enhanced Thematic Mapper Plus (ETM+) to examine signatures associated with damage from tornadoes and hail. They identified damage from the La Plata, Maryland, tornado on 28 April 2002, which was assigned a maximum rating of $\mathrm{F} 4$ and had a length (width) of $103.2(0.594) \mathrm{km}$. The tornado was identified in nearinfrared MODIS imagery and a 16-day MODIS NDVI composite as a nearly linear feature running west to east across the city. Image differencing techniques also were used to highlight the damage track, but alongtrack variations in land surface characteristics complicated the damage detection. Visual inspections of track length and maximum width were performed and compared to the official survey. ASTER and MODIS returned identical estimates of $33-\mathrm{km}$ path length, but ASTER coverage did not include the full length of the surveyed damage track. Maximum width was estimated at $500 \mathrm{~m}$ (two pixels) from MODIS data, but $1275 \mathrm{~m}$ in ASTER imagery. The 1275-m maximum width from ASTER exceeded the maximum width reported within the official survey, but the widest 
portion of the ASTER track occurred within an urban environment where diverse land use and land surface change contributed to a greater path width estimate where corroborating surface damage information was absent.

MODIS and Landsat-7 ETM+ imagery also was used to analyze tornado damage tracks near Ellsinore and Marquand, Missouri, from storms that occurred on 24 April 2002. The Ellsinore tornado track included agricultural areas near the community, as well as the Mark Twain National Forest, located to the southeast. Available damage survey information indicated F2 to F4 damage categories along a path length of $66.2 \mathrm{~km}$, ranging from 297 to $594 \mathrm{~m}$ in width, but detailed damage contours (as shown in Y02) were not provided. The Marquand tornado began near State Route 67 , continued eastward through a densely wooded area, and then struck the community, resulting in a path length of $14.5 \mathrm{~km}$ and maximum width of 732 $\mathrm{m}$-while also producing a swath of severe hail southeast of the tornado damage area. Landsat-7 ETM+ imagery was used in place of ASTER imagery for the analysis. Where MODIS and ETM+ data had similar coverage for the Missouri tornadoes, track lengths measured from each instrument were comparable, though ETM+ led to a narrower maximum width. Higher-resolution ETM+ imagery improved comparesons between satellite-based and surveyed width for the Ellsinore tornado, while measurements obtained from ETM+ (MODIS) slightly underestimated (overestimated) the maximum width of the Marquand track. J06 concluded that imagery from MODIS, ASTER, and ETM+ provide capabilities suitable for many aspects of storm-damage detection. The ability to detect a storm damage track depended in part on the underlying surface characteristics and tornado intensity, with detection likelihood increasing with tornado size and severity. Damage was readily apparent within regions of uniform land cover and growing vegetation that were struck by strong tornadoes or large, damaging hail.

An analysis of the Marquand, Missouri, storm track by J06 included vegetation and land surface change resulting from damage by severe hail. Molthan et al. (2013) reviewed previous applications of sensors of various resolutions, spectral bands, and repeat cycles, and then identified changes in vegetation resulting from a severe hail event across South Dakota, Nebraska, Iowa, and Missouri that occurred on 18 August 2011. Sharp, short-term NDVI change was noted within consecutive days of MODIS observa- tions, corroborated by radar-based and public reports of severe hail, and confirmed on field scales through use of higher-resolution sensors. NDVI changes between multi-day composites also were used to reveal and monitor the evolution of hail damage swaths across northwestern Iowa (Gallo et al. 2012). The relative susceptibility of vegetation to damage can depend upon the vegetation type, period of the growing season, and combined effects of wind (straight-line or tornado) and hail. Bentley et al. (2002) noted that satellite-based signals from Landsat-7 depended, in part, on vegetation type and susceptibility. Damaged swaths of vegetation may lead to mesoscale impacts on surface temperature and moisture, and localized impacts on future weather and the development of future storms. Parker et al. (2005) examined hail swaths in the Dakotas that occurred in July 2003. Hail-damage swaths were warmer $\left(+0.9^{\circ} \mathrm{C}\right)$, drier $\left(-0.3^{\circ} \mathrm{C}\right)$, and produced warmer infrared brightness temperatures than immediately adjacent, undamaged areas. Modeling studies by Parker et al. (2005) confirmed that damage swaths could strengthen future convective storms within ambient environments where low- and midlevel flow is parallel to the swath direction.

The aforementioned studies have demonstrated that satellite observations can identify land surface scarring resulting from severe weather, and that imagery can be useful when supplementing information collected in detailed ground surveys. Motivated by the previous use of imagery in the 27 April surveys (Molthan et al. 2011) and opportunities to provide additional data in support of future assessments, this study examined the usefulness of single-day NDVI imagery for identifying damage resulting from storms on 27 April across central and northern Alabama. Storm reports on 27 April included isolated reports of severe hail that may have contributed to vegetation scarring, but the widespread occurrence of long-track, damaging tornadoes was the dominant source of land surface scarring across central and northern Alabama. Visual inspection of single-day NDVI imagery emulates the potential use of simple, easily interpreted, near real-time data within the survey process. Satellitebased tornado damage tracks were compared against official NWS surveys to explore overall detection efficiency. Opportunities to compare satellite observations against detailed EF-scale contours were limited. The analysis of satellite-based tracks noted in NDVI imagery focused on (i) comparisons to officially surveyed track length and maximum width and (ii) the 
ability of single-day NDVI to detect at least portions of tracks among tornadoes of varying maximum estimated EF-scale damage that occurred across northern and central Alabama.

Selected portions of satellite-based tracks were examined as case studies to highlight challenges in track detection resulting from local heterogeneity of land cover and limited survey data, as well as a case where satellite imagery may have encouraged a follow-up survey. The co-location of a sufficiently detailed storm survey near Phil Campbell, Alabama, and cloud-free Landsat-7 imagery over multiple days permitted a more detailed examination of satellite-based damage detection. Principal component analysis and NDVIchange techniques were explored to improve understanding of vegetation change and future opportunities for improved detection. Procedures for assignment of an EF-scale to a given tornado are based upon tornado damage confirmed at the surface by trained survey teams, and no attempt is made herein to categorize a given tornado based upon satellite observations.

\section{Data and methods}

In response to severe weather events, numerous satellite assets are available for analysis. These products range from near real-time data distribution through NASA and NOAA direct readout capabilities or acquisition of imagery in partnership with other federal agencies. This study focused on the use of publically available NASA data acquired from the MODIS Level 1 and Atmosphere Archive and Distribution System (ladsweb.nascom.nasa.gov) and Landsat-7 ETM+ or ASTER data acquired from the United States Geological Survey (USGS) Earth Explorer (earthexplorer.usgs.gov) portal. Other commercially available satellite systems could provide additional capabilities at finer spatial resolution (1-5 m), but are beyond the scope of this study.

\section{a. Use of MODIS data}

The MODIS instruments aboard the NASA Terra and Aqua satellites provide red-visible and nearinfrared reflectance at 250-m spatial resolution. Imagery from MODIS is provided in near real-time from direct broadcast in 5-min granules with a swath width of $2330 \mathrm{~km}$, typically resulting in a twice-daily view of the affected area. The analysis herein focused on use of Terra MODIS observations, which provided late-morning imagery over the southeastern United States. Top-of-atmosphere radiances were converted to surface reflectance prior to NDVI calculations. Resulting NDVI values were scaled to an 8-bit grayscale image to aid in visual inspection. The use of satellite imagery requires clear skies over the affected area, and skies generally cleared from west to east across Alabama in the days following 27 April. Clear-sky images from Terra MODIS on 30 April and 4 May were used to identify possible tornado damage tracks.

\section{b. Landsat-7 Enhanced Thematic Mapper Plus (ETM+)}

Landsat-7 ETM+ provides near-infrared and redvisible reflectance at a spatial resolution of $30 \mathrm{~m}$ and samples the same ground location every 16 days within scenes measuring $183 \mathrm{~km} \times 170 \mathrm{~km}$. Given the limited view of an individual ETM+ scene and other orbital characteristics, several days of Landsat-7 orbits were necessary to provide statewide coverage for tornado track analysis: 4 May, 6 May, 20 May, 22 May, and 29 May 2011. In May 2003, the scan line corrector of the ETM+ failed, resulting in stripes of missing data near the edges of each granule, but remaining data are of high quality and useful in damage detection. Some images were collected several days beyond the initial event and after official survey activities largely concluded, but they were examined here as examples of Landsat ETM+ capabilities.

\section{c. The Advanced Spaceborne Thermal Emission and Reflection Radiometer (ASTER)}

ASTER provides red-visible, green-visible, and near-infrared reflectance at a higher spatial resolution $(15 \mathrm{~m})$ than either MODIS $(250 \mathrm{~m})$ or the ETM+ (30 $\mathrm{m})$, but temporal and spatial coverage is reduced. ASTER scenes are limited to $60 \mathrm{~km} \times 60 \mathrm{~km}$ and obtained at the same time as Terra MODIS imagery, but must be planned, requested, and scheduled for collection. Temporal coverage is typically reduced to time periods immediately following a disaster event. Given the large number of tornadoes across Alabama, ASTER imagery was collected over most of the state through late May and early June 2011. Imagery from 4 May, 20 May, 29 May, and 5 June 2011 were used in the analysis. Although well after the 27 April event, imagery from late May and early June demonstrates how ASTER can be applied to a broad variety of tornado damage tracks. 


\section{d. Satellite-based identification of tornado damage tracks}

For near real-time satellite imagery or derived products to be useful, damage tracks should be readily apparent to an analyst with limited prior knowledge of the severe weather event. NDVI imagery is relatively easy to interpret as increases (decreases) correspond to vegetation health (decay) and overall greenness (stress or damage). As described by Y02 and J06, damage tracks are observable as narrow regions of reduced NDVI along the general direction of the tornadogenerating thunderstorm where damaged vegetation is in contrast with healthy vegetation on either side. J06 noted decreases in NDVI values within the damage area of $0.05-0.1$, or a $10-15 \%$ reduction in NDVI when compared to adjacent, undamaged areas. Land surface heterogeneity and varying use types can affect satellite-based detection of tornado damage because track visibility requires a visible change in vegetation characteristics along the damage path. Weaker tornadoes (EF-0 to EF-2) may be more difficult to detect, as they are less likely to cause significant vegetation damage. In vegetated areas they may produce winds strong enough to snap tree limbs and uproot small or weakened trees, but they may not produce changes large enough to be seen within the spatial resolution of a MODIS, ETM+, or ASTER pixel. As tornado intensity increases, it is reasonable to expect increased damage to vegetation. Longer, wider tracks occupying greater numbers of sensor pixels should improve damage track contrast and aid in detection. Decreases in NDVI occurring immediately after a strong tornado are attributable to damage to, or destruction of, vegetation within the path, but longerterm effects also may be observed. Damaged vegetation may (i) grow at a slower rate than surrounding vegetation, (ii) be reduced in coverage within the pixel such as to reveal reflectance characteristics of underlying soils, (iii) undergo wilting and browning within the track area, or (iv) be removed during storm cleanup. Changes in NDVI over time can refine detections in these areas if sufficient cloud-free data are available (Y02).

Coauthors J. Bell and T. Cole visually inspected NDVI imagery from Terra MODIS, Landsat-7 ETM+, and Terra ASTER using GIS tools to create polygons outlining suspected damage tracks. Imagery was examined prior to consulting available storm tracks to reduce bias in track identification. After satellite-based damage tracks were identified, official surveys from the Huntsville and Birmingham WFOs were used to confirm that a suspected track was associated with a corresponding tornado from 27 April. This step eliminated some tracks that were attributable to other severe weather events earlier in the month (e.g., 15 April 2011) or even evidence persisting from previous years. For tornadoes where neither analyst could detect a signature in the satellite imagery, the official NWS damage survey was consulted to approximate the likely location of a possible damage track. Images were revisited to see if any signal could be detected, but no tracks were discovered after consulting the official NWS surveys. For tornadoes that crossed CWA boundaries, satellite-based tracks were split into segments representing each portion that occurred within a given CWA to match survey attributes provided by the individual WFOs.

\section{Satellite-based detection of surveyed tornado damage tracks}

For this outbreak, field surveys were provided for a total of 62 tornadoes, six of them split at CWA boundaries to create a total of 68 survey segments (Fig. 1). Figure 2 provides a broad view of MODIS imagery over Alabama where several tracks were apparent. Many tracks from particularly strong, longtrack tornadoes are apparent in the broad-view MODIS imagery across Alabama, and other tracks also were apparent at the full 250-m spatial resolution. Some of the damage tracks were only visible in single-day NDVI imagery by consulting higher-resolution ETM+ and ASTER imagery. To highlight differences in track visibility among sensors of varying resolution, Fig. 3 provides comparisons of track detection between MODIS, ETM+, and ASTER for a portion of the Phil Campbell, Alabama, damage path.

Table 1 and Fig. 4 summarize the characteristics of satellite-based tornado tracks among the three sensors. Ninety-five percent (66\%) of tornadoes with a maximum rating of $\geq \mathrm{EF}-3$ ( $\geq \mathrm{EF}-2)$ were detected, at least in part, by one or more satellite instruments. Satellite-based damage tracks were observed in at least one sensor for all tornadoes with maximum rating of $\geq$ EF-4. While the total percentage of detected tracks was relatively low (32\%), the majority of tornadoes that occurred $(71 \%)$ were of $\leq \mathrm{EF}-2$ estimated maximum rating - where aforementioned studies by $\mathrm{Y} 02$ and J06 determined that detection by single-day NDVI can be difficult. Only three of the 42 EF-1 and EF-2 surveyed tornadoes produced a satellite-based damage 


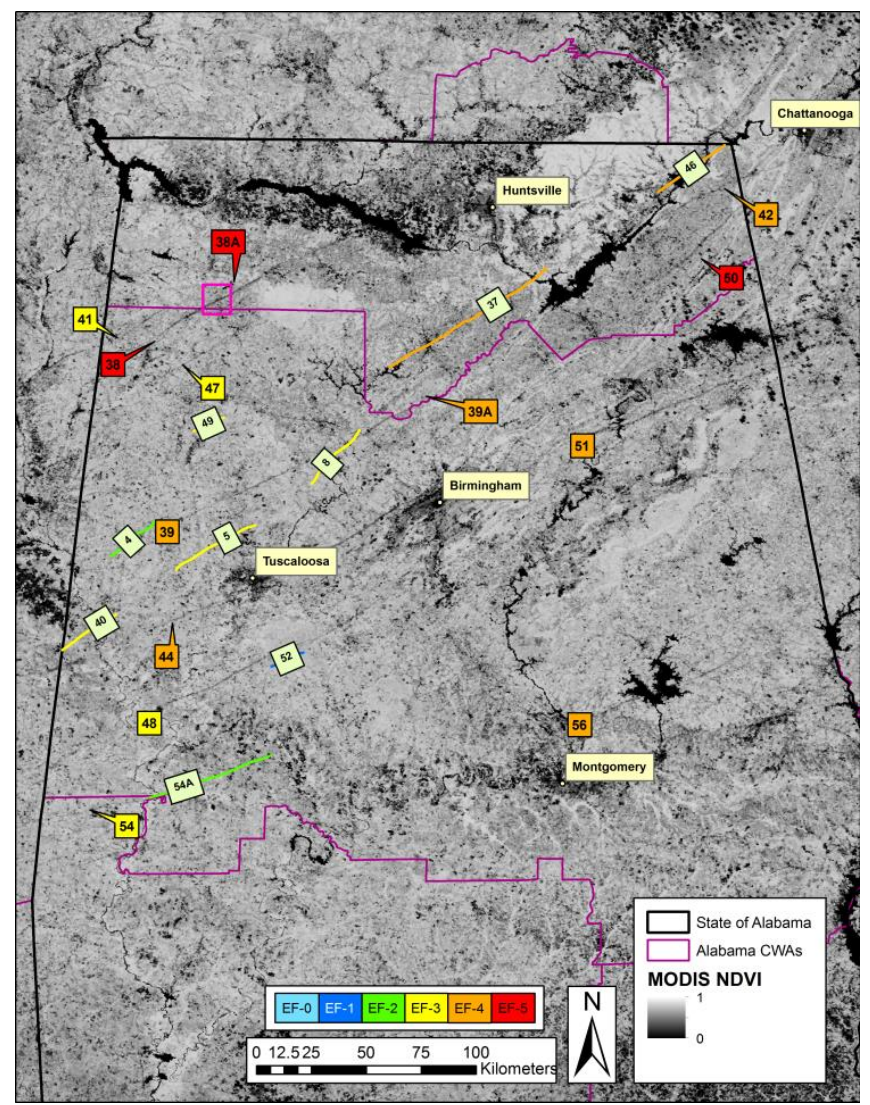

Figure 2. MODIS NDVI imagery collected on 4 May 2011-a clear sky morning following the 27 April 2011 outbreak. Tracks identifiable in this wide-zoom image are marked with arrows and numbers corresponding to information in Table 1. Colors of boxes indicate maximum estimated EF-scale rating. Other tracks that were identifiable by MODIS, but not readily apparent at this zoom level, are identified by a line and corresponding number listed in Table 1, as well as color-coded according to maximum estimated EF-scale. The red box in northwestern AL locates imagery shown in Fig. 3.

track, consistent with previous studies of lower-end tornadoes and the aforementioned limitations in detecting minor vegetation damage. Satellite-based damage tracks for EF-2 tornadoes were observed for the Northern Reform (\#4) and Pinhook (\#54A) tornadoes, but limited to ETM+ or ASTER imagery. Increases in sensor spatial resolution generally improved detection capabilities. Among the 68 surveyed tracks, only 16 (24\%) were identified using MODIS imagery, increasing to $21(31 \%)$ by ETM+, and $22(32 \%)$ by ASTER (Fig. 4). Improved detection with greater sensor resolution was particularly noticeable for tornadoes of EF-3 maximum rating. MODIS provided satellite-based damage tracks for five of the nine EF-3 tornadoes, with detections increasing to seven for ETM+ and eight for ASTER.
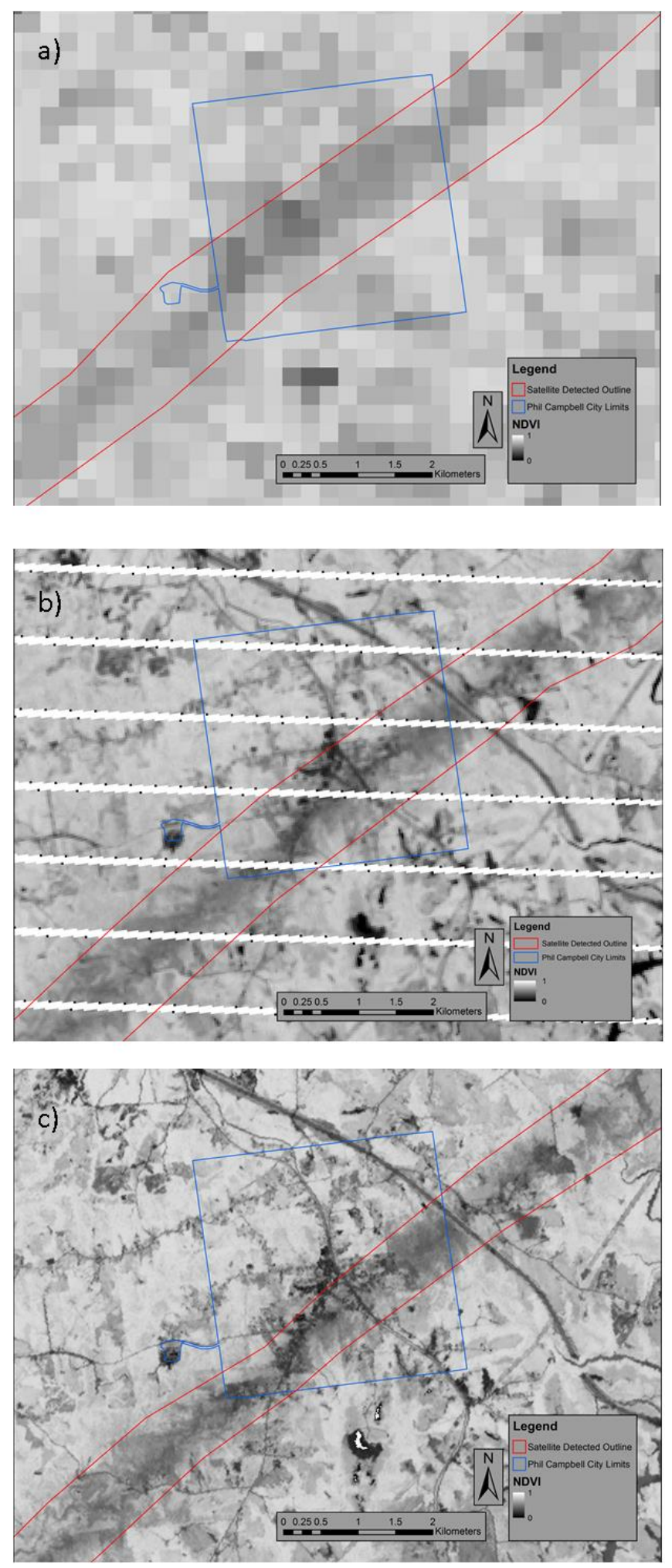

Figure 3. Comparison of single-day NDVI images from a) Terra MODIS on 4 May 2011, b) Landsat-7 ETM+ on 4 May 2011, and c) Terra ASTER on 20 May 2011, all focused on a portion of the damage track near Phil Campbell, AL (identified as a red inset box in Fig. 2). 


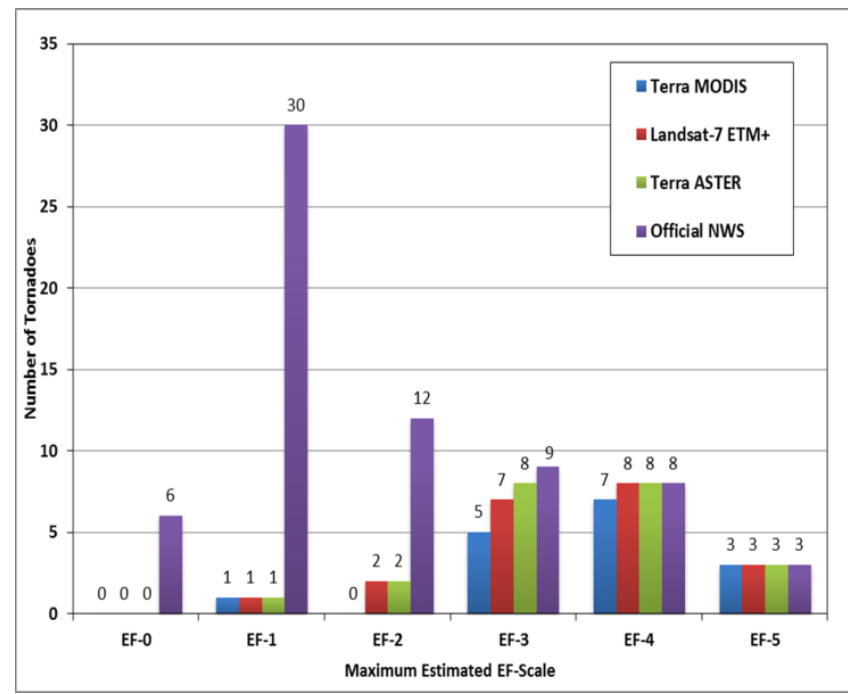

Figure 4. Distribution of the maximum estimated EF-scale of identified tornado damage tracks by satellite sensor, compared against official NWS surveys.

Overall, single-day, NDVI-based detections at resolutions of ASTER, ETM+, and MODIS suggest that tornadoes of EF-3 maximum rating represent a transition zone between detection and non-detection, with detection improving slightly with increases in spatial resolution. Detailed polygons of EF-scales would clarify this threshold if available from future storm surveys. For example, comparisons herein were based upon a maximum estimated rating even if the maximum rating was confined to a relatively small portion of the overall track. Within damage tracks of tornadoes of EF-3 maximum rating, areas of damage $<$ EF-3 are less likely to produce a discernible, short-term reduction in NDVI that results in a visible scar. Satellite-based detections from single-day NDVI imagery likely omitted some EF-0 to EF-2 damage areas, particularly if damage tracks from tornadoes of EF-3 maximum rating consisted primarily of lower-end EF-0 to EF-2 damage. For this reason, a surveyed track with a maximum rating of EF-2 or EF-3 may not have a corresponding satellite-based tornado track, as the majority of the surveyed damage would fall within the lower EF-0 to EF-2 categories where vegetation damage was not significant enough to produce a visible NDVI scar. Despite these limitations, the overall trend of increased satellite-based detection for maximum ratings of $\geq E F-3$ is generally consistent with previous analyses of a single, detailed tornado survey by Y02 and multiple tornadoes analyzed by J06.

\section{a. Comparison of satellite-based and surveyed path length}

After identifying all satellite-based damage tracks, their lengths were determined by measuring along the centerline through a polygon circumscribing the observed NDVI scar. Analysts noted that the identification of a satellite-based track from single-day NDVI imagery depended in part upon the contrast of the damage area against its surroundings. Accuracy also depended upon a subjective analysis of the imagery and the inference of track locations; no objective algorithm was applied. Lengths of satellite-based damage paths were comparable to those of the official survey lengths and produced relatively strong correlations $\left(\mathrm{R}^{2}\right.$ $=0.88-0.93$, Fig. 5). Correlations for ASTER results were reduced owing to a lack of data coverage for portions of some surveyed tracks for the Lake Martin and Shoal Creek tornadoes.

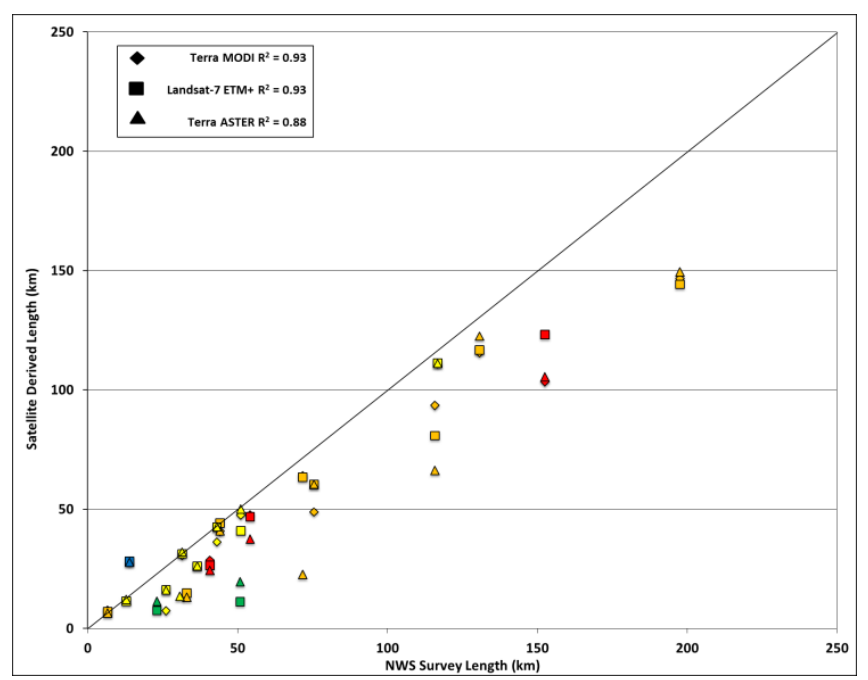

Figure 5. A comparison of surveyed and satellite-based tornado damage track path lengths as observed from MODIS, ETM+, and ASTER imagery. The solid line would indicate a perfect match between the survey length and satellite-based estimates.

Relatively strong correlations obscure important details regarding length comparisons. For the majority of satellite-based tracks, their lengths were shorter than survey measurements. Among tornadoes of EF-4 and EF-5 maximum rating, satellite-based lengths underestimated surveyed lengths by an average of 20 $\mathrm{km}$ for ETM+ and $23 \mathrm{~km}$ for MODIS and ASTER. Satellite-estimated lengths of the Hackleburg EF-5 (\#38) and Cordova EF-4 (\#39) tornadoes underestimated the official survey lengths by $25-40 \%$. The official surveys for these storms included portions of 
the tornado track with clusters of damage indicators at lower-end EF-scale ratings in areas without satellitedetected damage, contributing to an overall underestimate of the total path length. Length errors were quite large for $\geq \mathrm{EF}-3$ tornadoes with surveyed lengths $>75$ $\mathrm{km}$. Since single-day, NDVI-based detections were less likely in portions of the track with $\leq \mathrm{EF}-2$ ratings, satellite-based lengths may be truncated owing to omission of damage areas near the beginning and end of the track where the tornado is strengthening or decaying. For tornadoes of EF-3 maximum rating, length underestimates ranged from $6 \mathrm{~km}$ for ETM+ and ASTER to $15 \mathrm{~km}$ for MODIS. Length errors for weaker tornadoes can be obtained from information in Table 1. Detailed contours of EF-scale information would be required to improve conclusions regarding relationships between specific EF-scales, their detection efficiencies, and relationships to length errors.

\section{b. Comparison of satellite-based and surveyed path width}

Maximum widths of satellite-based tornado damage paths were estimated from reprojected imagery. During reprojection, satellite imagery was interpolated using nearest-neighbor techniques that preserved the resolution characteristics of each sensor rather than using interpolation schemes that would further smooth the imagery. GIS tools were used to measure perpendicularly across the widest portion of the satellitebased damage track, and no rounding was applied. Measurements were acquired from the centers of pixels perpendicular to and across the identified track. During the official survey process, maximum width was estimated perpendicularly across the widest point of the surveyed damage track, and then rounded to the nearest $402 \mathrm{~m}(0.25 \mathrm{mi})$. Full precision of survey widths (prior to rounding) would be preferable, but were not available. Comparisons of rounded and unrounded satellite-based widths were performed against survey results. Rounding of satellite-based widths did not significantly impact results or overall conclusions. Unrounded values are shown in Table 1 and discussed to emphasize differences in satellite-based tracks that resulted from different sensor resolutions.

Correlations of satellite-based and surveyed estimates of maximum width generally improved as image spatial resolution increased $\left(\mathrm{R}^{2}=0.39-0.52\right.$, Fig. 6); however, comparisons of satellite-based and surveyed maximum width were less favorable than estimates of path length. Isolated cases of ASTER imagery (e.g.,

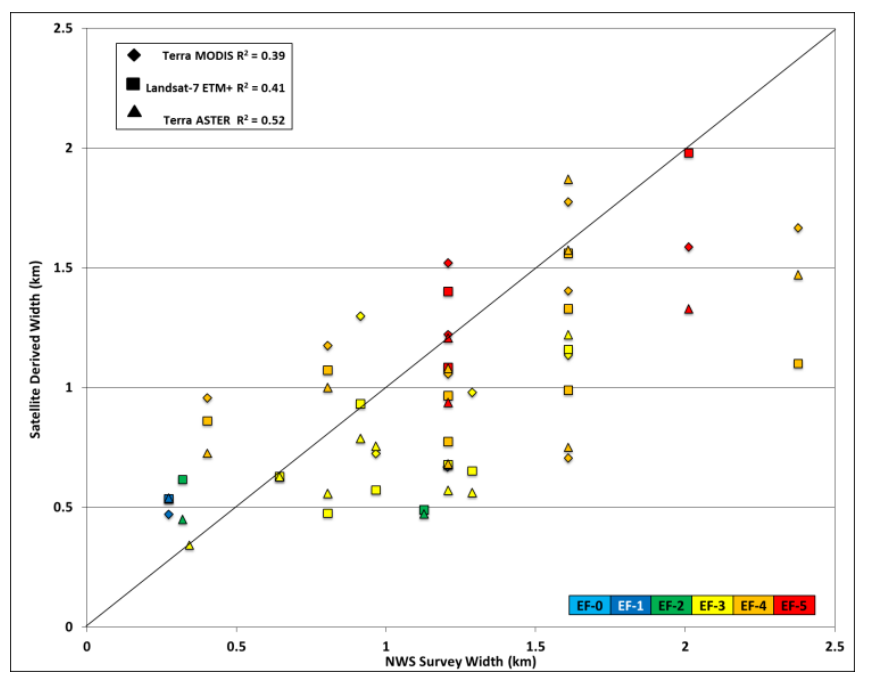

Figure 6. As in Fig. 5, but for comparisons of damage track maximum width.

Shoal Creek, \#51) included satellite-based widths greater than the official survey. In near real-time applications, image analyses might encourage a reassessment of maximum width, particularly if imagery provided information where surveyors could not access damage indicators. However, satellite-based tracks generally underestimated surveyed widths in most cases. Among tornadoes with maximum rating of $\geq \mathrm{EF}-4$, mean underestimates of width were $0.60 \mathrm{~km}$ for MODIS, $0.38 \mathrm{~km}$ for ETM+, and $0.43 \mathrm{~km}$ for ASTER. For tornadoes of EF-3 rating, mean underestimates of width were $0.47 \mathrm{~km}$ for MODIS, $0.39 \mathrm{~km}$ for ETM+, and $0.30 \mathrm{~km}$ for ASTER. In general, mean underestimates of width were improved when higherresolution sensors were available, with ETM+ and ASTER generally outperforming MODIS. Higherresolution sensors often provided additional detail within the gradient between damaged and undamaged areas, while the coarser MODIS pixels lacked sufficient detail to discern this gradient.

Consistent with visual inspections of satellitebased tracks from tornadoes with maximum rating of $\geq \mathrm{EF}-3$, it is likely that satellite-based estimates of maximum width failed to detect damage in the EF-0 to EF-2 range that occurred along the periphery of the surveyed tracks. Previous studies by Y02 and J06 concluded that damage often extends outward beyond the centerline of the satellite-based damage track, particularly at lower categories of EF-scale damage where vegetation damage and surface change is more difficult to detect. To a much lesser extent, satellite-based estimates of width also may differ from 
surveyed widths because analysts identified different locations as the widest point.

\section{c. Weaknesses and strengths of satellite-based track analysis}

To encourage a greater understanding of satellitebased damage detection, and in support of training potential users on the limitations of applying singleday NDVI imagery to damage track detection, selected tracks were examined as brief case studies for discussion in greater detail. Our analysis focused on specific damage surveys that included estimated EF-scale polygons based upon greater numbers of available damage indicators.

An EF-5 tornado struck Phil Campbell, Alabama, and continued northeast toward the Tennessee River. As the tornado approached the river from the southwest, it produced a track apparent in ASTER imagery (Fig. 7). Land use along the Tennessee River consists mainly of agriculture (Fig. 8), evident as an irregular pattern of low-to-medium NDVI values corresponding to shapes of fallow fields and bare soil, or fields lacking sufficient spatial density of green vegetation. Although the track was visible on the southwestern side of the Tennessee River, it was not visible among fields on the northeastern side of the river. The satellite-based track remained elusive until the tornado crossed more densely vegetated, higher NDVI areas north of United States Highway 72 and east of Interstate 65 where land-use patterns are residential or suburban with greater and more uniform coverage of trees and other green vegetation. In total, nearly $18 \mathrm{~km}$ of the surveyed track was not detected by single-day NDVI imagery because of insufficient contrast between the damaged vegetation and surrounding, undamaged areas. Damage of EF-3 to EF-4 was reported within the missing portion of the satellite-based track northeast of the Tennessee River. Results from tracks of similar rated tornadoes in Alabama and aforementioned studies suggest that a satellite-based track should have been evident given sufficient coverage and greenness of the underlying vegetation. It is hypothesized that a track of similar rating would be apparent just northeast of the Tennessee River had the storm occurred later in the growing season when crops and dense vegetation are present.

The Bridgeport tornado track was classified with a maximum rating of EF-4, but EF-4 damage was confined to the southern portions of the city (Fig. 9). The majority of the track in rural Alabama was classified

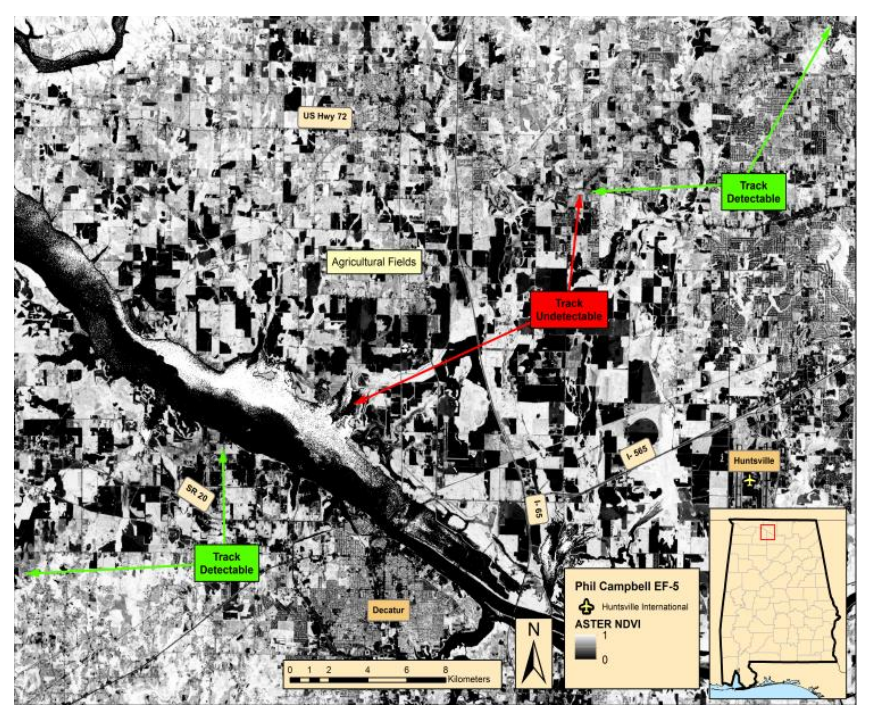

Figure 7. Detailed examination of a portion of the Phil Campbell EF-5 tornado damage track across north-central AL. Background NDVI imagery is provided by ASTER on 4 May 2011. Green arrows indicate the satellite-based damage track. Red arrows indicate where the track was not visible.

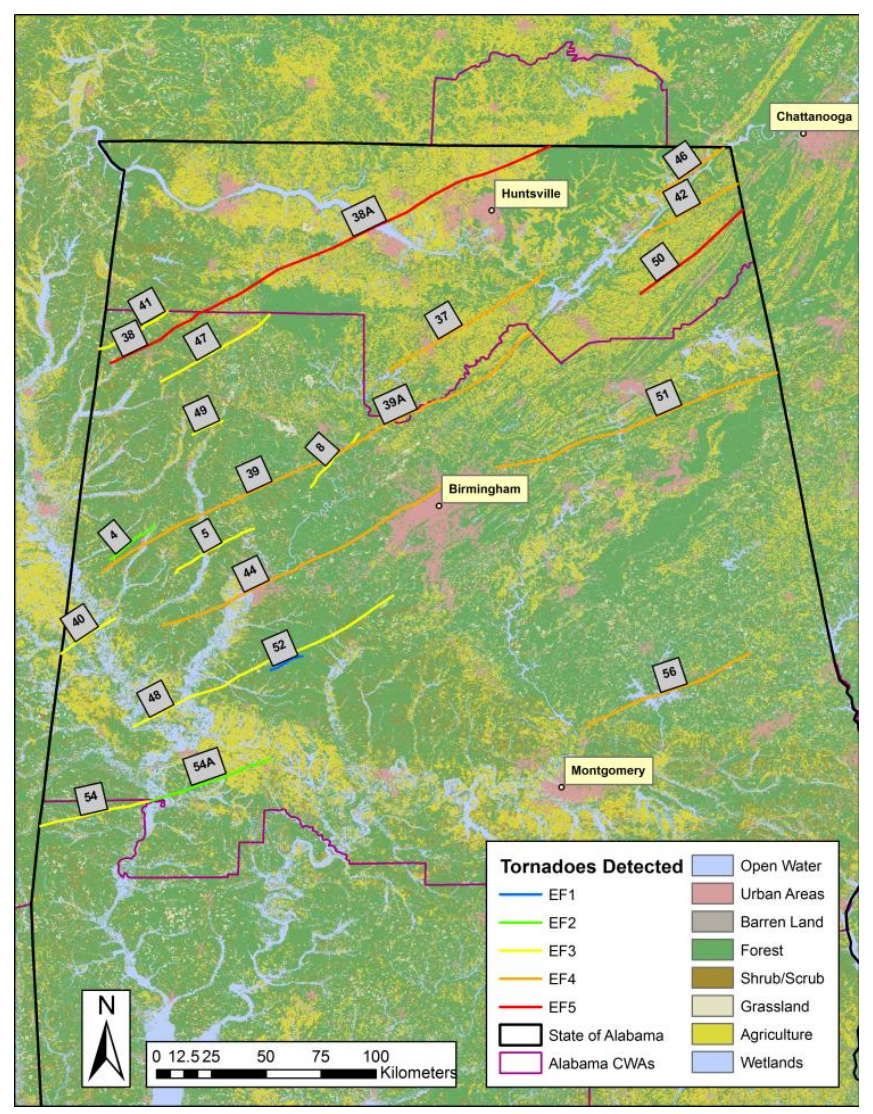

Figure 8. Primary land use classes throughout the state of AL, from the National Land Cover Dataset 2006 (Fry et al. 2011). Data categories from NLCD have been aggregated to a smaller number of major categories. 


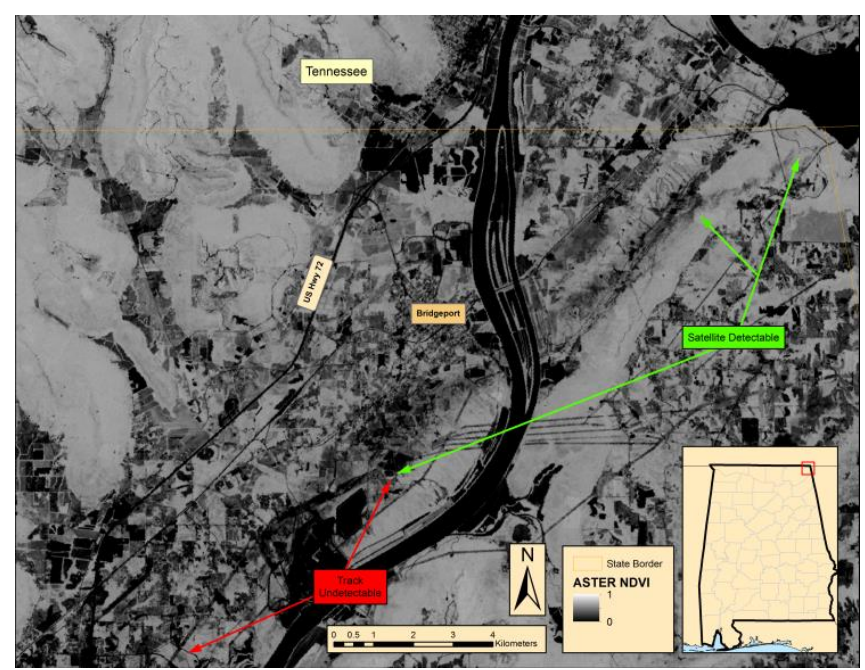

Figure 9. An example of the Bridgeport EF-4 tornado shown in ASTER NDVI imagery from 29 May 2011. Green arrows identify areas within the image where the satellite-based track is visible. Red arrows identify portions that were not visible but were included in the official survey.

as $\leq$ EF-2 rating. In addition, northeastern Alabama exhibits diverse land cover and complex terrain, resulting in a heterogeneous background of rapidly changing vegetation, land use types, and terrain between the southernmost extent of the Appalachians and the Tennessee River (Fig. 8). Complex scenes with rapidly varying vegetation types challenged track detection in J06 and caused similar problems in northeastern Alabama. In this instance, detection was limited to the area of greatest damage (EF-4, near Bridgeport) and within areas of relatively homogeneous vegetation, land use, and flat terrain where abrupt changes in NDVI could be identified visually. These factors resulted in a much shorter satellite-based length and poor estimation of the tornado maximum width.

Portions of the Phil Campbell and Bridgeport tracks highlight difficulty in detecting strong tornadoes, but despite occasional challenges, detection of weak tornadoes is sometimes possible. Single-day NDVI imagery revealed a damage scar associated with an EF-1 tornado (Wateroak, \#52, Fig. 10). This case provides an example of how satellite imagery could motivate a follow-up review of a completed damage survey. Based upon the scarring apparent in an ASTER NDVI image acquired on 4 May, it appears that the Wateroak tornado may have started approximately $8 \mathrm{~km}$ southwest of the actual survey and continued northeast beyond the official track by approximately $6.5 \mathrm{~km}$. Limited road networks, other obstructtions, or time limitations may have truncated this

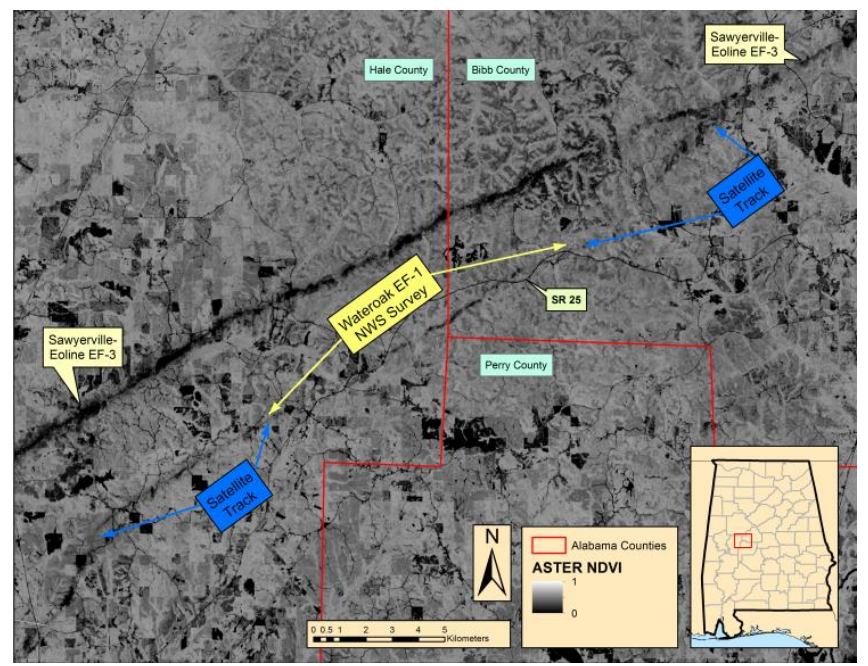

Figure 10. An example of the Wateroak EF-1 tornado shown in ASTER imagery from 4 May 2011. The yellow arrows identify the track along State Route 25 that was included in the official survey. The blue arrows identify other areas adjacent to the survey track where a scar is evident.

ground survey. For example, much of the surveyed track follows State Route 25, but as the highway deviates from the satellite-observed track, the survey track ends. If local road access limited this survey, a satellite-based assessment may have motivated a follow-up visit.

\section{d. Exploring techniques to improve satellite-based damage track detection}

The previous case studies and overall detection statistics highlighted some limitations of single-day NDVI imagery for identifying portions of surveyed tracks, especially in areas of EF-0 to EF-2 maximum rating. Meanwhile, previous studies have highlighted other methods of damage detection with other strengths and weaknesses. For example, short- and long-term NDVI change can improve detection, but requires cloud-free pre-storm imagery, or greater latency as additional data are collected over a multiday period. Other image-enhancement techniques, such as principal component analysis, may improve visibility of damage tracks, but the most useful component may vary with changes in satellite scene and thus result in imagery requiring complex interpretation. The Phil Campbell, Alabama, survey and cloud-free Landsat-7 ETM+ imagery from 2010 and 2011 were used to evaluate principal-component image enhancement and short- to long-term NDVIchange techniques proposed by Y02. Application of ETM+ imagery over the Phil Campbell area examines 
how these methods may improve immediate detection of damage areas, how continued debris removal may impact short-term NDVI differencing techniques, and how longer-term NDVI differencing may improve the detection of damaged areas.

Clear-sky views were obtained from the Landsat-7 ETM+ over Phil Campbell, Alabama, on 4 May and 20 May. The 16-day repeat cycle of Landsat-7 allowed for similar viewing angles and illumination. Although ETM+ provides seven bands for analysis, top-ofatmosphere reflectance from bands 2 (green), 3 (red), and 4 (near-infrared) on 4 May were selected to approximate the imager bands of the LISS-III instrument used by $\mathrm{Y} 02$ and to construct three principal components (Table 2). Values of each principal component were linearly scaled to 8-bit values so that the resulting tornado damage scar would appear relatively dark, consistent with other imagery.

Table 2. Summary of the principal component analysis results the for Landsat-7 ETM+ scene acquired on 4 May 2011 in northwestern AL.

\begin{tabular}{|l|c|c|c|}
\hline Principal Component & $\mathbf{1}$ & $\mathbf{2}$ & $\mathbf{3}$ \\
\hline Eigenvalue & $5.23 \mathrm{E}-03$ & $8.93 \mathrm{E}-04$ & $2.20 \mathrm{E}-05$ \\
\hline & \multicolumn{3}{|c|}{ Eigenvectors } \\
\hline $\begin{array}{l}\text { Band 2 (green, 0.25-0.60 } \\
\boldsymbol{\mu m})\end{array}$ & -0.055 & -0.16 & 0.985 \\
\hline $\begin{array}{l}\text { Band 3 (red, 0.63-0.69 } \\
\boldsymbol{\mu m})\end{array}$ & -0.557 & -0.814 & -0.164 \\
\hline $\begin{array}{l}\text { Band 4 (near-infrared, } \\
\text { 0.77-0.90 } \boldsymbol{\mu m})\end{array}$ & 0.829 & -0.558 & -0.045 \\
\hline Variation explained & $85.20 \%$ & $14.50 \%$ & $0.36 \%$ \\
\hline
\end{tabular}

To explore NDVI-change detection, NDVI from 4 May was differenced against NDVI obtained on 20 May. This short-term difference was used to characterize the magnitude of change that occurred within and along the satellite-based damage track. Short-term NDVI differencing clarifies the impact of possible data latency on the appearance of the damage scar. Longterm NDVI change was calculated by differencing values from 4 July 2010 and 20 May 2011. To quantify the differences in various parameters within and outside of the damage area, means and standard deviations were calculated for pixels falling within the surveyed EF-scale contours for the region shown in Fig. 11. Undamaged background pixels were obtained by considering all remaining pixels falling outside the surveyed EF-scale contours in Fig. 11a.

Single-day NDVI imagery from 4 May 2011 is shown in Fig. 11a, replicating the imagery originally used to obtain Landsat-7 ETM+ track characteristics shown in Table 1. The track identified in the ETM+ imagery is shown alongside detailed polygons of EF-0, EF-2, and EF-4 rating that were mapped during the damage survey. Reduced NDVI values (dark shades) are apparent within the satellite-based track. Portions of the satellite-based track were slightly wider than the outermost EF-0 survey contour. The corridor of reduced NDVI values in the 4 May image generally falls within the contour of $\geq \mathrm{EF}-2$ damage identified by the official survey. Mean values and standard deviations of NDVI within the various EF-scale polygons generally decrease with increasing damage category-by vegetation damage and scouring (Table 3). In the southwestern corner of Fig. 11a, the surveyed EF-0 contour and the satellite-based tracks differ markedly at the Franklin and Marion County lines, which also serve as the boundary between the Huntsville and Birmingham WFOs. This may have occurred as survey teams from each WFO merged the two surveys across the CWA boundary.

Qualitative examination of principal component imagery (Figs. 11b-d) suggested that the damage track contrast was best enhanced by the second and third principal components. Even though PC2 (Fig. 11c) and PC3 (Fig. 11d) only explained $14.5 \%$ and $0.36 \%$ of the total scene variation, respectively, qualitative examination of the resulting PC3 image yields improved damage track contrast over PC1 (Fig 11b). Consistent with the resulting imagery, mean values of PC3 decreased with increasing EF-scale (Table 3). Small gaps occurred within the satellite-based tracks for the NDVI image, PC2, and PC3. Forested areas may have been more susceptible along the track relative to intermittent areas of grasses or agricultural uses, leading to gaps in satellite-based signals despite a continuous survey track. For portions of the satellite-based track that overlapped with the official survey, darkened areas of the PC2 and PC3 images often fell within the EF-2 to EF-4 contours. The tight spacing of the EFscale contours did not allow for detailed inference of where satellite-based signals ceased within that range, but the appearance of the satellite-based signal degrades sharply in the EF-0 to EF-2 interval.

The analysis of short-term NDVI changes between 4 and 20 May indicate that data latency may result in NDVI changes associated with debris removal rather than association with storm damage (Fig. 11e). Widespread and consistent vegetation wilt, or decrease in greenness and NDVI, did not continue within the damage track during the intervening 16-day period. Vegetation thoroughly scoured by the tornado already con- 

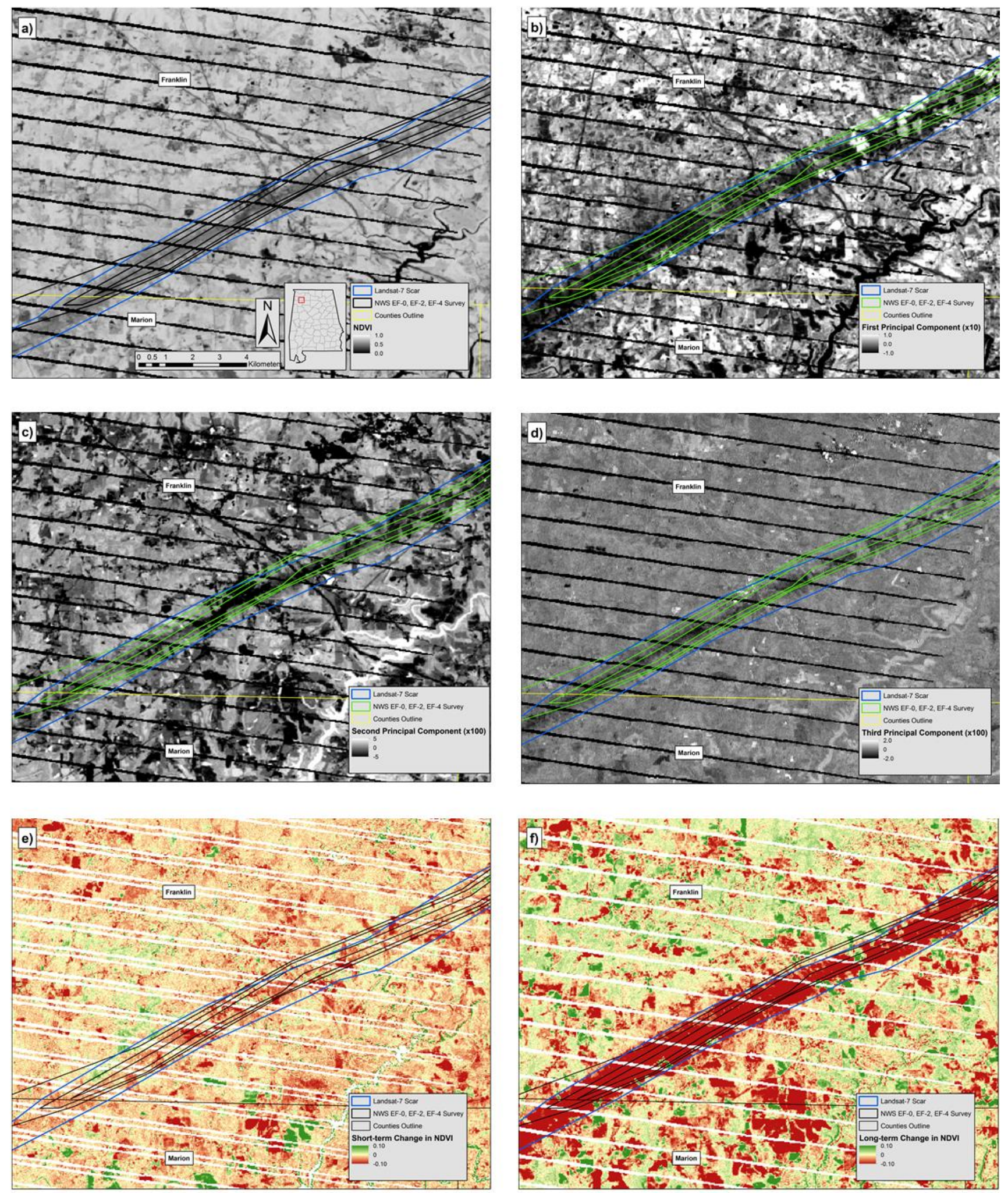

Figure 11. Additional image analyses performed for the Phil Campbell, AL, area based upon imagery from Landsat-7 ETM+. a) NDVI from 4 May; b) first principal component derived from 4 May imagery and characteristics in Table 2; c) as in b), but for the second principal component; d) as in b), but for the third principal component; e) short-term change in NDVI between 4 May and 20 May 2011; and f) long-term change in NDVI between 4 July 2010 and 20 May 2011. In each figure, the original Landsat-7 ETM+ satellite-based damage track is outlined along with EF-scale polygons at EF-0, EF-2, and EF-4 ratings provided by the storm survey. 
Table 3. Means $(\mu)$ and standard deviations $(\sigma)$ of selected parameters within and external to a portion of the tornado damage survey near Phil Campbell, AL. The number of image cells used in NDVI differencing is approximately $10 \%$ less than shown here owing to differences in Landsat-7 scan line corrector outages (striping) that differ between data periods. Cell count values here are shown for 4 May 2011 observations.

\begin{tabular}{|c|c|c|c|c|c|c|c|c|c|}
\hline \multirow{2}{*}{$\begin{array}{l}\text { EF-Scale } \\
\text { (Survey) }\end{array}$} & \multirow{2}{*}{$\begin{array}{c}\text { Image } \\
\text { Cells } \\
(30 \mathrm{~m}) \\
\end{array}$} & \multicolumn{2}{|c|}{ Third Principal Component } & \multicolumn{2}{|c|}{ NDVI on 4 May 2011} & \multicolumn{2}{|c|}{ Short-term NDVI Change } & \multicolumn{2}{|c|}{$\begin{array}{c}\text { Long-term NDVI } \\
\text { Change }\end{array}$} \\
\hline & & $\mu(\mathrm{x} 100)$ & $\sigma(x 100)$ & $\mu$ & $\sigma$ & $\mu$ & $\sigma$ & $\mu$ & $\sigma$ \\
\hline 0 & 2430 & -0.009 & 0.405 & 0.626 & 0.118 & -0.027 & 0.039 & -0.111 & 0.122 \\
\hline 1 & 5292 & -0.150 & 0.376 & 0.618 & 0.115 & -0.021 & 0.034 & -0.114 & 0.115 \\
\hline 2 & 3085 & -0.290 & 0.488 & 0.567 & 0.116 & -0.030 & 0.036 & -0.190 & 0.124 \\
\hline 3 & 2918 & -0.260 & 0.579 & 0.573 & 0.124 & -0.032 & 0.039 & -0.178 & 0.133 \\
\hline 4 & 3493 & -0.370 & 0.530 & 0.546 & 0.109 & -0.034 & 0.036 & -0.211 & 0.128 \\
\hline 5 & 1321 & -0.650 & 0.465 & 0.454 & 0.096 & -0.051 & 0.048 & -0.291 & 0.105 \\
\hline Background & 236870 & 0.480 & 0.362 & 0.694 & 0.129 & -0.021 & 0.041 & -0.018 & 0.078 \\
\hline
\end{tabular}

tributed to low NDVI in the imagery of 4 May and continued decreases would be minor. Larger decreases in short-term NDVI change occurred for increases in surveyed EF-scale (Table 3). Areas with significant damage and higher EF-scale category may have produced greater amounts of debris that required immediate clearing, leading to greater short-term changes in NDVI. Debris removal activities likely contributed to isolated pockets of sharp change, resulting from the combined effects of vegetation decay and the clearing of storm debris. Numerous debris burns were visible in true-color MODIS imagery in the days and weeks following the 27 April event (not shown). Relationships between surface debris, their removal, and changes in NDVI could be an opportunity for future study. The satellite-based damage area also includes some isolated pockets of NDVI increase, largely on the outskirts of the satellite-based track where vegetation damage may have been relatively minor and was not a deterrent to the normal, seasonal green-up. Since post-storm cleanup activities can modify the land surface, analysts must use caution with delayed observations and consult other aspects of the imagery (e.g., true color) to understand if vegetation change is the result of debris clearing or burning activities.

The longer-term NDVI-change image draws immediate attention to the damage area (Fig. 11f). Consistent with visual comparisons between the short- and long-term NDVI-change images, the magnitudes of long-term NDVI decrease were greater across all EFscale categories, while the magnitude of background values remained similar (Table 3). Areas of sharp, long-term NDVI decrease filled the majority of the EF-2 to EF-5 contours, but a gradient remained apparent in the EF-0 to EF-2 range. The sharp NDVI change present in the long-term difference image is offset slightly from the official survey track in some areas. This offset makes it difficult to directly compare the EF-scale contours and NDVI change, but among the single-day NDVI images, principal component enhancements, and NDVI differencing techniques, the long-term NDVI difference image produced the sharpest depiction of the surveyed damage area. This encourages the use of longer-term NDVI change for improved damage detection, similar to the findings of Y02. Applications of longer-term NDVI change may be limited unless there is a means of rapidly acquiring seasonally similar, cloud-free imagery that is representative of pre-storm conditions. Numerous, other areas of sharp NDVI change are located throughout the scene as a result of land clearing for new subdivisions and agricultural activities, but the shapes and clustering of these features sets them well apart from the tornado damage track.

In general, inference of damage areas from singleday NDVI imagery for the most detailed portion of the Phil Campbell, Alabama, survey corresponded well with previous analyses by Y02 and J06. Satellite-based damage tracks generally were apparent within the $\geq \mathrm{EF}-2$ contours, particularly in well-vegetated areas. Long-term NDVI change dramatically improved the appearance of the damage scar within the $\geq E F-2$ contours. NDVI-based detections, whether single-day or NDVI change, are relatively straightforward since the derivation remains the same over time and interpretation can focus on impacts to vegetation health and greenness.

Principal components derived from three ETM+ bands did provide some additional clarity to the damage area. Y02 emphasized use of PC2, but the visual contrast between the Phil Campbell damage area and surroundings was best presented by PC 3 in this study. Scars were evident in both PC2 and PC3, however, and generally corresponded to damage categories of 
$\geq$ EF-2. Principal component analysis may prove useful as an image-enhancement technique, but interpretation of the resulting imagery is not as straightforward as NDVI or NDVI change. The principal component that offers the best contrast will likely vary between scenes owing to their relative complexity, specific land surface types, and signatures present in the input bands.

\section{Conclusions}

The tornado outbreak of 27 April 2011 led to significant urban and rural damage throughout much of central and northern Alabama. Satellite imagery was used to identify tornado damage tracks via single-day NDVI imagery obtained from Terra MODIS, Landsat7 ETM+, and Terra ASTER. Satellite-based damage tracks were identified when disrupted vegetation created a localized change readily visible with basic image-enhancement techniques and located along the path of the parent storm. Relationships were examined to understand the likelihood of detecting damage areas within tornadoes of varying maximum estimated ratings. Lengths and widths of satellite-based tornado tracks were compared against official survey measurements. Other techniques for improving track detection were explored for a highly detailed track in northwestern Alabama, revealing that long-term NDVI change may improve track detections. In conclusion, this study confirmed the following:

- MODIS, ETM+, and ASTER imagery was capable of identifying damage tracks resulting from tornadoes of varying estimated maximum rating. In this regional study of Alabama tornadoes that occurred on 27 April - and from imagery collected in the month that followed-most tornadoes with maximum rating of $\geq \mathrm{EF}-3$ produced detectable damage for at least some portion of their path length and maximum width, with some limited cases of detections for portions of path lengths and widths for tornadoes of EF-0 to EF-2 maximum rating.

- Satellite-estimated lengths were well correlated to surveyed lengths but significant errors were noted for particularly strong, long-track tornadoes of maximum rating $\geq E F-3$, where significant disruption to vegetation occurred and was consistent along the path. Since surveyed tornado path lengths included lower-end damage/rating areas where satellite signals are not always apparent, underestimates of length were frequent. Previous results suggest that damage detection in the EF-0 to EF-2 range from single-day NDVI can be difficult, and given that comparisons are made against maximum rating anywhere within the survey track, it seems reasonable to conclude that satellite-based estimates were lacking detection of some EF-0 to EF-2 damage areas. Comparisons of satellite-based and surveyed widths were less favorable than length. Satellite-based detections herein likely were missing regions of lower EF-scale damage along the track periphery, contributing to underestimates of maximum width and reduced correlations between satellite-based metrics and official surveys.

- Satellite-based signals can identify areas requiring follow-up or that can be used to extend tracks beyond areas accessible from the ground. This may be particularly valuable for ensuring the continuity of tracks across CWA boundaries or to encourage the reassessment of tornado surveys that may have been truncated because of access limitations.

- Characterization of tornado damage tracks from satellite remote sensing is generally, but not always, improved through increased spatial resolution. Finer-scale resolution details from ASTER $(15 \mathrm{~m})$ and ETM+ $(30 \mathrm{~m})$ were noted versus the coarser resolution $(250 \mathrm{~m})$ of MODIS.

- Weaker tornadoes with maximum rating of EF-0 to EF-2 were not often detected in single-day NDVI imagery analyzed herein, but there were some cases where detection was possible. Detected, weak tornadoes were apparent when the background vegetation types were relatively homogeneous. Broader statements of the impact of land surface heterogeneity on overall track detection capabilities would require additional damage analyses and detailed polygons of varying ratings that were not generally or uniformly available for all tornadoes examined in this study. In this study, final survey polygons were used as provided; however, there may be future opportunities for a more detailed hand analysis to improve EF-scale detail within some surveys that provide sufficient data. Otherwise, it is expected that future surveys and use of the NWS DAT will provide much more detail useful for comparing satellite-based tracks and survey information.

- Other image-enhancement and damage-detection capabilities were explored along the Phil Campbell, Alabama, tornado track where the survey provided reasonably detailed EF-scale contours. Longer-term NDVI differencing of immediate post-event image- 
ry and data from approximately one year prior produced the most obvious damage scar and features that were well-aligned with the damage survey. Principal component analysis of post-event imagery offered slight improvements to track visibility but may be scene-dependent, as the principal component providing the best contrast for damage in Phil Campbell differed from results of Y02-despite the use of similar spectral bands and spatial resolution.

- An analysis of the 27 April events and previous studies have thus far focused on observations in late April and early May, and satellite-based detections from storms at other times of the year may differ from these general conclusions, particularly because the satellite sensors employed focus on detections requiring local changes in vegetation. Vegetation characteristics vary regionally or seasonally, and different types of vegetation will have varying degrees of susceptibility to modes of severe weather or tornado intensity.

Higher spatial resolution sensors from commercial assets and future NASA or NOAA satellite platforms may improve detection, particularly in urban areas. Satellite-based analyses can be conducted in near-realtime, off-site, and made available through tools such as the NWS Advanced Weather Interactive Processing System, GIS and web-mapping systems, or integration within the NWS DAT in both desktop and mobile device displays (Camp et al. 2010). It is unlikely that satellite-based assessments could replace detailed inperson surveys because publically available imagery currently is insufficient for EF-scale categorization or full capture of a tornado path length and width. Instead, satellite-derived products can provide a supplemental source of information to aid in the overall assessment process, helping to confirm positions of tracks or highlighting opportunities to refine surveys accumulated among various survey teams. These datasets may be particularly valuable following significant outbreaks where the logistics of large numbers of surveys and limited staffing require additional resources. Future work will focus on supporting and extending damage-detection capabilities, reducing product laten$\mathrm{cy}$, and facilitating the use of satellite imagery within the assessment process.

Acknowledgments. Coauthor Tony Cole was supported by the NASA Summer Internship Program at NASA Marshall Space Flight Center in Huntsville, Alabama. Support for the remaining coauthors was provided through the Dis- asters focus area of the NASA Applied Sciences Program. Imagery from ASTER and ETM+ was provided through the USGS Earth Explorer portal. The authors thank their USGS collaborators for continued support of disaster-response imagery. Three anonymous reviewers contributed substantial, thorough, and helpful comments that dramatically improved the layout, clarity, and content of the revised manuscript.

\section{REFERENCES}

Bentley, M. L., T. L. Mote, and P. Thebpanya, 2002: Using Landsat to identify thunderstorm damage in agricultural regions. Bull. Amer. Meteor. Soc., 83, 363-376.

Camp, J. P., K. Stellman, and J. Settelmaier, 2010: Utilizing mobile devices for enhanced storm damage surveys. Preprints, 26th Conf. on Integrated Information Processing Systems (IIPS) for Meteorology, Oceanography, and Hydrology, Atlanta, GA, Amer. Meteor. Soc., 5B.4. [Available online at ams.confex.com/ams/ 90annual/webprogram/Paper161540.html.]

Fry, J., and Coauthors, 2011. Completion of the 2006 National Land Cover Database for the conterminous United States. Photogramm. Eng. Remote Sens., 77, 858-864. [Available online at www.mrlc.gov/ downloadfile2.php?file=September2011PERS.pdf.]

Gallo, K., T. Smith, K. Jungbluth, and P. Schumacher, 2012: Hail swaths observed from satellite data and their relation to radar and surface-based observations: A case study from Iowa in 2009. Wea. Forecasting, 27, 796802, CrossRef.

Jedlovec, G., 2013: Transitioning research satellite data to the operational weather community: The SPoRT paradigm. IEEE Geosci. Remote Sens. Mag., 3, 62-66. [Available online at www.goes-r.gov/resources/Scipubs/ docs/2013/SPoRT_IEEE_Magazine.pdf.]

, U. Nair, and S. L. Haines, 2006: Detection of storm damage tracks with EOS data. Wea. Forecasting, 21, 249-267, CrossRef.

Knupp, K. R., and Coauthors, 2014: Meteorological overview of the devastating 27 April 2011 tornado outbreak. Bull. Amer. Meteor. Soc., in press, CrossRef.

Molthan, A., G. Jedlovec, B. Carcione, 2011: NASA satellite data assist in tornado damage assessments. Eos, $\mathbf{9 2}$, 337-339, CrossRef.

, J. E. Burks, K. M. McGrath, and F. J. LaFontaine 2013: Multi-Sensor examination of hail damage swaths for near real-time applications and assessment. $J$. Operational Meteor., 1 (13), 144-156, CrossRef.

Myint, S. W., M. Yuan, R. S. Cerveny, and C. P. Giri, 2008: Comparison of remote sensing image processing techniques to identify tornado damage areas from Landsat TM data. Sensors, 8 (2), 1128-1156, CrossRef.

NOAA, 2011: Service assessment: The Historic Tornadoes of April 2011. National Weather Service, 76 pp. [Avail- 
able online at www.nws.noaa.gov/om/assessments/pdfs/ historic tornadoes.pdf.]

NWS, cited 2011: Pertinent geographic information systems (GIS) data from the April 27th, 2011 outbreak. National Weather Service, Birmingham, AL. [Available online at www.srh.noaa.gov/bmx/?n=event_04272011gis.]

Parker, M. D., I. C. Ratcliffe, and G. M. Henebry, 2005: The July 2003 Dakota hailswaths: Creation, characteristics, and possible impacts. Mon. Wea. Rev., 133, 1241-1260, CrossRef.

Speheger, D. A., C. A. Doswell III, and G. J. Stumpf, 2002: The tornadoes of 3 May 1999: Event verification in central Oklahoma and related issues. Wea. Forecasting, 17, 362-381, CrossRef.

Texas Tech University, 2004: A recommendation for an enhanced Fujita scale (EF-scale). Texas Tech University, Lubbock, TX, 95 pp. [Available online at www.spc.noaa.gov/faq/tornado/ef-ttu.pdf.]

Tucker, C. J., and J. A. Gatlin, 1984: Monitoring vegetation in the Nile Delta with NOAA-6 and NOAA-7 AVHRR imagery. Photogramm. Eng. Remote Sens., 50, 53-61.

Yuan, M., M. Dickens-Micozzi, and M. A. Magsig, 2002: Analysis of tornado damage tracks from the 3 May tornado outbreak using multispectral satellite imagery. Wea. Forecasting, 17, 382-398, CrossRef. 